\title{
Discriminação de assinaturas geoquímicas por meio de modelos de regressão e sistema de informações geográficas: estudo de caso no Vale do Ribeira (SP)
}

\author{
Jose Maria Filippini Alba ${ }^{1}$ \& Carlos Roberto Souza Filho ${ }^{2}$
}

\begin{abstract}
Resumo O Vale do Ribeira é um antigo distrito de mineração de $\mathrm{Pb}$ no Brasil, onde ocorre uma anomalia regional de As associada a depósitos de metais preciosos e de base. Esse estudo tem como objetivo caracterizar a resposta geoquímica regional de $\mathrm{Pb}$-As e analisar dados adquiridos na área de influencia da mina de $\mathrm{Pb}$ de Furnas visando explicar qual o impacto da atividade de mineração na constituição da assinatura geoquímica. Para tanto, foram utilizados dados geoquímicos de sedimentos de corrente coletados na década de 80 no Vale do Ribeira. Modelos de regressão para $\mathrm{As} \mathrm{e} \mathrm{Pb}$ foram produzidos em ambiente SIG considerando o método das microbacias. A análise dos dados permitiu demonstrar que a ocorrência de óxidos de ferro, de rochas máficas e de mineralizações metálicas na região são fatores que exercem controle na variância geoquímica, viabilizando a modelagem dos dados. As anomalias geoquímicas constatadas nas proximidades da mina Furnas sugerem um padrão geoquímico diferenciado do padrão regional, o qual é possivelmente relacionado com as atividades de mineração.
\end{abstract}

Palavras-chave: geoquímica, ambiente, elementos traço, mineração.

\begin{abstract}
Discrimination of geochemical patterns through regression models and geographical information system: a case study in the Ribeira Valley, state of São Paulo, Brazil. The Ribeira Valley is an ancient Brazilian lead mining district where a kilometric As regional anomaly is known to be related to precious and base metal deposits. Stream sediment geochemical data collected during the 80 's in the Ribeira Valley were considered in this study. The focus was two-fold: (i) regional geochemical characterization and (ii) use of data closely related to the Furnas $\mathrm{Pb}$ mine in an attempt to explain how mining activities may affect geochemical signatures. Regression models for $\mathrm{As}$ and $\mathrm{Pb}$ were applied in a GIS environment considering the sub-watershed method. The occurrence of iron oxides, mafic rocks and metallic mineralizations in the region proved to be key factors that control the geochemical variance and were here employed to guide the modeling. Geochemical $\mathrm{Pb}$-As anomalies verified at the Furnas mine strongly suggest a distinguished geochemical pattern, possibly related to mining activities.
\end{abstract}

Keywords: geochemistry, environment, trace elements, mining activities.

INTRODUÇÃO A discriminação da assinatura geoquímica natural da assinatura associada a processos antrópicos pode ser potencialmente caracterizada por meio de métodos estatísticos multivariados com suporte de um Sistema de Informações Geográficas (SIG), principalmente pelo fato de que a distribuição espacial dos dados torna-se relevante nesse contexto. Entre os métodos estatísticos, os mais empregados são a análise de regressão por mínimos quadrados(Selinus \& Esbensen 1995) e análise fatorial e das correlações canônicas (Korre 1999a,b).

Duas das principais características do setor Paulista do Vale do Ribeira são o potencial mineral, principalmente para $\mathrm{Pb}$, e a abundância de recursos biológicos, com destaque para a ampla reserva de Mata Atlântica, um dos principais remanescentes do Brasil. Esses aspectos, de certa maneira conflitantes do ponto de vista ambiental, orientaram as pesquisas na região nos últimos anos. Trabalhos de prospecção geoquímica desenvolvidos pela CPRM (Addas \& Vinhas 1975; Morgental et al. 1975; Morgental et al. 1978; Silva et al. 1981) no Médio Vale do Ribeira demonstraram a ocorrência de uma anomalia regional de As relacionada à Unidade Piririca (Perrotta \& Campos Neto 1999). Geotecnologias foram aplicadas em estudos prospectivos no Médio Vale do Ribeira, na tentativa de avaliar o potencial aurífero regional (Perrotta 1996; Moura 1997). Outros estudos focaram aspectos da Geoquímica Ambiental (Da Silva 1997; Moraes 1997; Toujague 1999) ou foram direcionados para Geologia Médica (Paoliello 2002; Cunha 2004).

O método das microbacias (Bonham-Carter 1994) foi introduzido por meio de SIG, na tentativa de aprimorar o processamento de dados geoquímicos de sedimentos de corrente com enfoque prospectivo, de maneira a reconhecer a influência da orientação dos cursos hídricos. Para um dado elemento, uma estatística das amostras interiores é considerada como representativa do teor da microbacia. O método foi aplicado para prospecção de Au no Vale do Ribeira considerando-se como representativo de cada micro-bacia, o teor máximo entre as amostras circunscritas em seus limites (Perrotta 1996; Moura 1997). O uso de microbacias como unidades ambientais é recomendado por diversos 
autores em função da homogeneidade dos materiais e processos que ocorrem no seu interior (Beltrame 1994).

Considerando a média como a estatística representativa do teor da microbacia, o método das microbacias pode ser relacionado ao Teorema do Limite Central, postulado importante da Estatística, cujo enunciado pode ser redigido da seguinte maneira: "se subconjuntos aleatórios de amostras são extraídos de uma população qualquer, e são calculadas as médias de cada subconjunto, a população das médias possui maior tendência a uma distribuição de Gauss ou normal, que a população original" (Davis 1986).

$\mathrm{O}$ exposto acima sugere que para uma dada variável geoquímica, o teor de fundo (background) pode ser avaliado de maneira mais eficiente quando considerada a população das médias de cada microbacia, devido a maior tendência à normalidade. Entende-se por teor de fundo, o valor representativo do teor de um elemento químico (ou associação de elementos) em uma divisão do espaço físico, por exemplo, um domínio geológico ou uma microbacia. Nesse caso, é possível considerar o teor de fundo regional ou teor de fundo local, respectivamente, pois há um fator de escala envolvido no conceito. É comum usar a média ou a mediana das amostras associadas a um domínio geológico para avaliar o teor de fundo regional. Em locais específicos o teor de um ou mais elementos pode ser diferenciado devido à ocorrência de uma rocha peculiar, uma mineralização ou um fenômeno de diluição. Esse teor é denominado de teor de fundo local, que pode estar relacionado a uma anomalia positiva (acima do teor de fundo regional) ou negativa (abaixo do teor de fundo regional).
Neste estudo, métodos estatísticos e de análise espacial foram aplicados de maneira integrada sobre dados geoquímicos multi-elemento de sedimentos de corrente na área de pesquisa, inserida no Vale do rio Ribeira. Os dados foram transformados pelo método das microbacias com o auxílio de um SIG, objetivando caracterizar a assinatura geoquímica natural (seja ela derivada do teor de fundo regional ou da ocorrência de mineralizações), modelar a informação e discriminar a assinatura provocada pela influência antrópica, principalmente aquela relacionada à mineração. Paralelamente, o trabalho aborda ainda a eficiência do método das microbacias em relação ao método convencional de processamento de dados geoquímicos.

ÁREA DE PESQUISA A área de estudo abrange duas folhas 1/50.000, Iporanga e Gruta do Diabo, localizadas no Vale do rio Ribeira, na região da fronteira entre os Estados de Paraná e São Paulo. Iporanga e Barra do Turvo são os principais centros urbanos inseridos na área de pesquisa (Fig. 1). A economia regional é baseada na agropecuária de sobrevivência, no extrativismo e no turismo ecológico, em função da beleza paisagística, que envolve áreas de conservação de Mata Atlântica e ambiente cárstico.

A geologia regional (Perrotta 1996) consiste de seqüências supracrustais orientadas segundo a direção geral NE-SW e inclue faixas metassedimentares de unidades terrígenas, químicas e clastoquímicas, com intercalações de rochas vulcânicas e subvulcânicas básicas atribuídas ao Super-Grupo Açungui. Corpos granitóides sin a tardi-orogênicos cortam essas faixas. No pe-

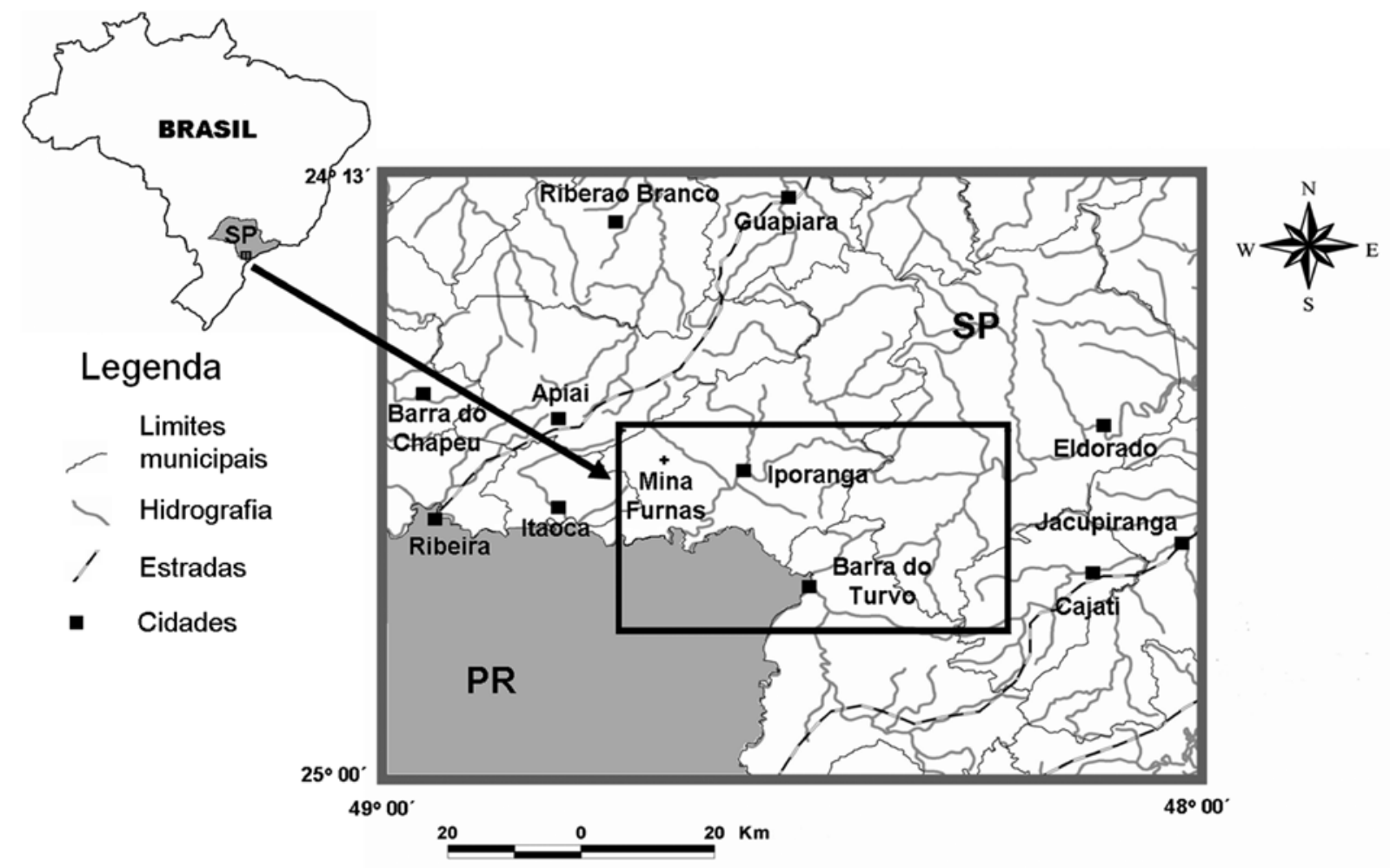

Figura 1 - Localização da área de pesquisa. 
ríodo Mesozóico, ocorreu magmatismo básico fissural associado à tectônica de abertura do oceano Atlântico e a reactivação da Plataforma Brasileira, com a intrusão do enxame de diques básicos do Arco de Guapiara.

A "Unidade Piririca" foi definida informalmente (Perrota \& Campos Neto 1999) e trata-se de uma seqüência metavulcano-sedimentar composta de metabasanitos, filitos carbonosos e carbonáticos que hospeda várias ocorrências auríferas. Existe uma anomalia regional de As em sedimentos de corrente e solos associada à Unidade Piririca, indicada por estudos prospectivos pioneiros desenvolvidos pela CPRM (Addas \& Vinhas 1975; Morgental et al. 1975; Morgental et al. 1978; Silva et al. 1981).

A mina Furnas, localizada no setor NW da área de pesquisa (Fig. 1), é relacionada a veios epigenéticos discordantes das rochas carbonatadas hospedeiras, de idade Mesoproterozóica (Silva et al. 1981). A mineralização, composta principalmente por galena argentífera, esfalerita e pirita, é controlada por feições estruturais. A datação radiométrica $\mathrm{Pb}-\mathrm{Pb}$ em galena indicou 1.1 - 1.4 Ga. para a idade da mineralização. A exploração mineral $(\mathrm{Pb}$ e $\mathrm{Ag})$ foi suspensa em 1992, devido a problemas técnicos (Moraes 1997).

FONTES DE DADOS E MÉTODOS A base de dados disponível para o estudo foi organizada no ambiente de um SIG e comprendeu:

(i) dados geográficos em escala 1:250.000, envolvendo hidrografia, limites municipais, localização das cidades e rede viária (Joly 1999); (ii) dados geoquímicos de sedimentos de corrente pretéritos (Addas \& Vinhas 1975; Morgental et al. 1975; Morgental et al. 1978; Silva et al. 1981, Instituto de Pesquisa Tecnológica do Estado de São Paulo - IPT, inédito); (iii) o modelo digital de elevação - MDE (Shuttle Radar Topographic Mission - SRTM, NASA); (iv) ocorrências minerais (Perrotta 1996). O sistema de projeção utilizado foi o Universal Transverso de Mercator (UTM), região 22 Sul, com o datum Córrego Alegre.

As amostras geoquímicas escolhidas para o estudo (IPT, inédito) correspondem à fração inferior a 80 mesh de sedimentos de corrente e foram analisadas para 25 elementos: As por espectrometria de absorção atômica; F por eletrodo seletivo; $\mathrm{Ca}, \mathrm{Fe}, \mathrm{Mg}$, Ti, B, Ba, $\mathrm{Be}, \mathrm{Co}, \mathrm{Cr}, \mathrm{Cu}, \mathrm{La}, \mathrm{Li}, \mathrm{Mn}, \mathrm{Mo}, \mathrm{Nb}, \mathrm{Ni}, \mathrm{Pb}, \mathrm{Sn}, \mathrm{Sr}, \mathrm{V}$, $\mathrm{Y}, \mathrm{Zn}$ e Zr por espectrometria ótica de emissão.

O MDE foi gerado a partir do levantamento realizado pela Shuttle Radar Topographic Mission (SRTM), em fevereiro de 2000, por meio de interferometria de radar; possui resolução horizontal de $\sim 90 \mathrm{~m}$ e vertical de $\sim 10 \mathrm{~m}$ (Souza Filho 2003). O MDE permitiu delimitar as microbacias hidrográficas com o auxílio do módulo Watershed do software ArcGIS(ESRI 1999). A hidrografia foi sobreposta ao mapa de microbacias visando uma avaliação criteriosa de sua consistência espacial. Cada amostra geoquímica foi designada a uma microbacia, por meio da integração das tabelas de atributos do arquivo raster com a do arquivo de pontos.

As microbacias foram organizadas segundo dois conjuntos, conforme estudo prévio com dados de sedi- mentos de corrente do Vale do Ribeira (Filippini Alba et al. 2003). As microbacias com área média inferior $\mathrm{e}$ superior a $20 \mathrm{~km}^{2}$ foram consideradas, respectivamente, representativas de fenômenos locais (microbacias A) e do fundo geoquímico regional (microbacias B). As 111 microbacias A derivadas a partir do MDE-SRTM apresentam área média de $8,5 \mathrm{~km}^{2}$ e variação de área de 3-31 $\mathrm{km}^{2}$. As 50 microbacias B, por sua vez, têm área média de $32 \mathrm{~km}^{2}$ e variação de área de $3-109 \mathrm{~km}^{2}$. O método das microbacias foi aplicado considerando-se a média das amostras interiores como representativas do teor de cada microbacia para um dado elemento.

Segundo o modelo de diluição (Hawkes 1976), o teor de um elemento em uma amostra de sedimentos de corrente no exutério de uma microbacia pode ser relacionado ao teor de fundo (background) da microbacia, à área da microbacia e à ocorrência de mineralizações. O modelo adequar-se-ia às situações onde existe um forte controle da dispersão mecânica sobre a variabilidade geoquímica, em função da participação da área de microbacia, que se associa à erosão.

Cumpre destacar que a área de pesquisa experimentou uma intensa atividade de mineração de $\mathrm{Pb}$ antes de 1992 (Moraes 1997). Além disso, ocorre uma anomalia regional de As em sedimentos de corrente e solos da "Unidade Piririca" (Perrota \& Campos Neto 1999). Trata-se de uma situação peculiar, que integrada à disponibilidade de dados multifonte no local e a influência do homem em uma pequena área (mina Furnas), viabilizou a modelagem da distribuição espacial de ambos os elementos, fato que potencializa a possível discriminação da influência de fenômenos naturais em relação aos relacionados com a ação humana.

$\mathrm{O}$ uso do modelo das microbacias possibilitou incorporar a área de microbacia na modelagem de regressão, imitando o modelo de diluição, sendo também usadas a declividade da microbacia e vários elementos químicos. Foi considerada sempre uma equação linear multivariada do tipo (equção 1):

$$
\mathrm{Y}=\Sigma \mathrm{c}_{\mathrm{i}} \mathrm{X}_{\mathrm{i}}+\mathrm{K} \quad \mathrm{i}=1,2,3 \ldots
$$

onde Y é a variável dependente, ou seja, o teor de As ou de $\mathrm{Pb}$ avaliado pelo modelo para uma dada microbacia; $\Sigma$ simboliza a soma consecutiva dos produtos $c_{i} X_{i} ; c_{i}$ e $K$ são parâmetros determinados pelo cálculo; $X_{i}$ representa as variáveis independentes, ou seja, a área, a declividade ou o teor de um elemento para a microbacia.

Previamente ao cálculo dos modelos deve ser observada a ocorrência de outliers, isto é, amostras inconsistentes com o conjunto dos dados (Gnanadesikan \& Kettenring 1972), que podem prejudicar avaliações posteriores (Fig. 2). A ocorrência de outliers foi evidenciada pela observação dos diagramas de dispersão. As mesmas foram eliminadas ou tiveram seus efeitos reduzidos a partir da transformação logarítmica. Uma vez processadas as outliers, foram elaborados novos diagramas de dispersão, que permitiram detectar a ocorrência de subpopulações de amostras de compor- 


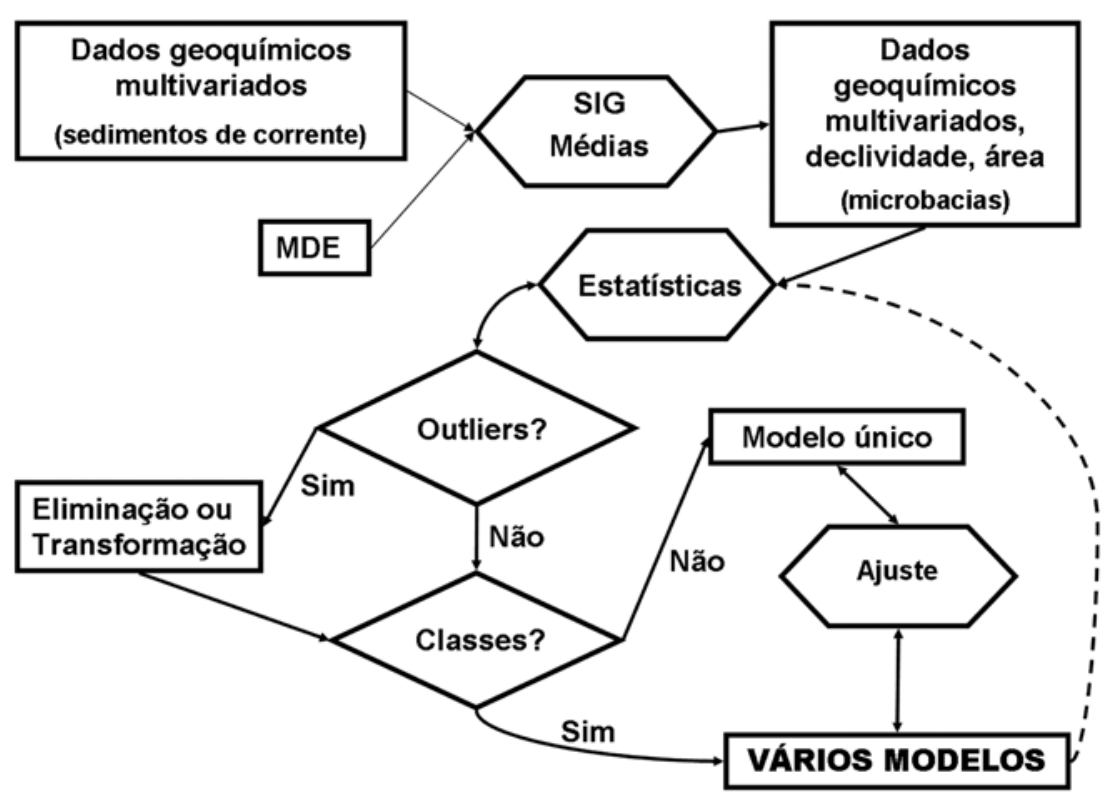

Figura 2 - Quadro explicativo do processo estatístico aplicado.

tamento homogêneo, denominadas classes. No caso de existirem várias classes, os modelos de regressão são calculados para cada uma das mesmas.

Como foram calculados vários modelos para cada variável dependente (As ou $\mathrm{Pb}$ ), foi desenvolvido um procedimento para avaliar qual deles era o mais adequado, o qual se denominou "Ajuste" (Fig. 2). Assim, foram considerados: (1) a Variância explicada pelo modelo (VEX), que representa o percentual de variância que o modelo consegue explicar e está relacionado à soma do quadrado das diferenças entre os valores calculados para a variável dependente e a média real da classe; (2) a estatística F, que é a razão entre VEX e a variância residual, ou seja, a soma do quadrado das diferenças entre os valores da variável dependente avaliados e os valores reais; (3) os valores dos coeficientes, $\mathrm{c}_{\mathrm{i}}$ e K na eq.1, sendo descartados modelos com algum $\mathrm{c}_{\mathrm{i}}$ negativo, por dedução lógica.

Os resultados do processamento estatístico, desde a geração dos dados físicos das microbacias até a definição das classes, foram executados para as microbacias A e as microbacias B de maneira independente e serão expostos à continuação.

\section{PROCESSAMENTO ESTATÍSTICO EXPLORA- TÓRIO}

Estatísticas univariadas Na tabela 1 são apresentados os limites de detecção, as medianas e os extremos das amostras de sedimentos de corrente consideradas (IPT inédito). Os elementos $\mathrm{Be}, \mathrm{La}, \mathrm{Li}, \mathrm{Mo}$ e $\mathrm{Sn}$ foram fortemente afetados pelos limites de detecção, sendo descartados de analises posteriores. No caso dos elementos $\mathrm{Ca}, \mathrm{As}, \mathrm{B}, \mathrm{Co}, \mathrm{Cu}, \mathrm{F}, \mathrm{Nb}, \mathrm{Ni}, \mathrm{Sr}, \mathrm{V}, \mathrm{Y}, \mathrm{Zn}$ e Zr, os limites de detecção foram substituídos por $50 \%$ do seu valor para aplicações estatísticas.

Na tabela 2 são apresentadas às estatísticas avaliadas para as microbacias. Destaca-se a maior variabi- lidade da área das microbacias (54-62\%) em relação à declividade (14-17\%). Os elementos $\mathrm{Mn}, \mathrm{As}, \mathrm{B}, \mathrm{Ba}, \mathrm{Cr}$, $\mathrm{Pb}$ e $\mathrm{Zn}$ apresentam médias maiores para as microbacias A em relação as microbacias B. $\mathrm{Cu}, \mathrm{F}, \mathrm{Nb}, \mathrm{Ni}, \mathrm{Sr}$ e $\mathrm{Zr}$ indicam uma situação oposta. Os coeficientes de variação foram sempre inferiores para as microbacias B.

Análise das dependências entre as variáveis geoquímicas Na tabela 3 são apresentados os coeficientes significativos de correlação de Spearman (Davis 1986), para os teores dos elementos representativos das microbacias. Observou-se uma forte correlação de vários teores de elementos traços com o Fe, confirmada pelos diagramas de dispersão. Fe-Mn evidenciaram uma nítida correlação positiva para as microbacias A (Fig. 3a), diferenciando-se dos elementos que apresentaram comportamento mais próximo ao do As-Pb (Fig. 3c), que sugere a ocorrência de várias sub-populações. Observa-se que o uso da transformação logarítmica (Figs. $3 \mathrm{~b}$ e 3d) diminui a dispersão para altos valores, mas a aumenta para valores inferiores a unidade. Para as microbacias B houve uma redução da dispersão (Figs. 3e e 3 f), porém, sendo conservado um padrão de semelhança com os gráficos das microbacias A.

Análise das dependências entre as variáveis físicas e geoquímicas A área de microbacia e a declividade apresentaram baixas correlações, 0,06 e -0,18, para as microbacias A e B, respectivamente. A área de microbacia não apresentou correlação significativa com nenhuma variável geoquímica; o maior coeficiente de correlação foi de 0,26 para o Ba (microbacias B). No caso da declividade, as correlações com os elementos $\mathrm{Mg}, \mathrm{Cu}, \mathrm{Ni}$ e $\mathrm{Zn}$ foram positivas, com coeficiente de correlação variando no intervalo $0,32-0,42$ para as microbacias $\mathrm{A}$, sendo que houve um decréscimo para as microbacias $\mathrm{B}$, com coeficientes de correlação variando 
Discriminação de assinaturas geoquímicas por meio de modelos de regressão e sistema de informações geográficas: estudo de caso no Vale do Ribeira (SP)

Tabela 1 - Limites de detecção, medianas e extremos dos teores das amostras de sedimentos de corrente consideradas neste estudo (IPT, inédito).

\begin{tabular}{c|c|c|c|c|c}
\hline Elemento & LD & Mínimo & Mediana & Máximo & Unidade \\
\hline $\mathrm{Fe}$ & 0,05 & 0,2 & 4,1 & 11 & $\%$ \\
$\mathrm{Ca}$ & 0,05 & $<0,05$ & 0,13 & 9,4 & $\%$ \\
$\mathrm{Mg}$ & 0,02 & 0,02 & 0,35 & 6,4 & $\%$ \\
$\mathrm{Ti}$ & 0,002 & 0,03 & 0,7 & 6 & $\%$ \\
$\mathrm{Mn}$ & 10 & 80 & 1300 & $>5000$ & $\mathrm{ppm}$ \\
$\mathrm{As}$ & 1 & $<1$ & 11 & 550 & $\mathrm{ppm}$ \\
$\mathrm{B}$ & 10 & $<10$ & 110 & 1100 & $\mathrm{ppm}$ \\
$\mathrm{Ba}$ & 10 & 15 & 480 & 2100 & $\mathrm{ppm}$ \\
$\mathrm{Be}$ & 1 & $<1$ & $<1$ & 24 & $\mathrm{ppm}$ \\
$\mathrm{Co}$ & 2 & $<2$ & 18 & 130 & $\mathrm{ppm}$ \\
$\mathrm{Cr}$ & 5 & 6 & 76 & 660 & $\mathrm{ppm}$ \\
$\mathrm{Cu}$ & 3 & $<3$ & 35 & 320 & $\mathrm{ppm}$ \\
$\mathrm{La}$ & 20 & $<20$ & $<20$ & 1400 & $\mathrm{ppm}$ \\
$\mathrm{Li}$ & 50 & $<50$ & $<50$ & $\leq 50$ & $\mathrm{ppm}$ \\
$\mathrm{Mo}$ & 3 & $<3$ & $<3$ & 34 & $\mathrm{ppm}$ \\
$\mathrm{Nb}$ & 10 & $<10$ & 25 & 180 & $\mathrm{ppm}$ \\
$\mathrm{Ni}$ & 5 & $<5$ & 32 & 180 & $\mathrm{ppm}$ \\
$\mathrm{Pb}$ & 10 & $<10$ & 26 & 2500 & $\mathrm{ppm}$ \\
$\mathrm{Sn}$ & 5 & $<5$ & $<5$ & 37 & $\mathrm{ppm}$ \\
$\mathrm{Sr}$ & 5 & $<5$ & 48 & 850 & $\mathrm{ppm}$ \\
$\mathrm{V}$ & 5 & $<5$ & 97 & 600 & $\mathrm{ppm}$ \\
$\mathrm{Y}$ & 10 & $<10$ & 27 & 230 & $\mathrm{ppm}$ \\
$\mathrm{Zn}$ & 2 & $<2$ & 81 & 990 & $\mathrm{ppm}$ \\
$\mathrm{Zr}$ & 10 & $<10$ & 260 & $>5000$ & $\mathrm{ppm}$ \\
$\mathrm{F}$ & 30 & $<30$ & 425 & 1600 & $\mathrm{ppm}$ \\
\hline & & & & &
\end{tabular}

Tabela 2 - Médias e Coeficientes de Variação (CV) para os conjuntos de microbacias e para a população total. $N$ = número de espécimes (amostras).

\begin{tabular}{c|c|c|c|c|c|c}
\hline \multirow{2}{*}{$\begin{array}{c}\text { Variável } \\
\text { (unidade) }\end{array}$} & \multicolumn{2}{|c|}{$\begin{array}{c}\text { Geral } \\
(\mathrm{N}=763)\end{array}$} & \multicolumn{2}{c|}{$\begin{array}{c}\text { Microbacias } \mathrm{N} \\
(\mathrm{N}=111)\end{array}$} & \multicolumn{2}{c}{$\begin{array}{c}\text { Microbacias B } \\
(\mathrm{N}=50)\end{array}$} \\
\cline { 2 - 7 } & Média & $C V$ & Média & $C V$ & Média & $C V$ \\
\hline Área $\left(\mathrm{km}^{2}\right)$ & Não & Não & 8,5 & $54 \%$ & 32 & $62 \%$ \\
\hline Declividade $\left.{ }^{\circ}\right)$ & Não & Não & 16 & $17 \%$ & 16 & $14 \%$ \\
\hline Elevação (m) & Não & Não & 353 & $45 \%$ & 387 & $40 \%$ \\
\hline $\mathrm{Fe} \mathrm{( \% )}$ & 4,6 & $51 \%$ & 4,5 & $37 \%$ & 4,5 & $34 \%$ \\
\hline $\mathrm{Ca}(\%)$ & 0,3 & $246 \%$ & 0,3 & $153 \%$ & 0,3 & $130 \%$ \\
\hline $\mathrm{Mg}(\%)$ & 0,4 & $88 \%$ & 0,4 & $66 \%$ & 0,4 & $49 \%$ \\
\hline $\mathrm{Ti}(\%)$ & 0,9 & $79 \%$ & 0,9 & $52 \%$ & 0,9 & $46 \%$ \\
\hline $\mathrm{Mn}(\mathrm{ppm})$ & 1870 & $78 \%$ & 1796 & $58 \%$ & 1708 & $55 \%$ \\
\hline $\mathrm{As}(\mathrm{ppm})$ & 23 & $199 \%$ & 22 & $154 \%$ & 20 & $93 \%$ \\
\hline $\mathrm{B}(\mathrm{ppm})$ & 137 & $84 \%$ & 138 & $53 \%$ & 137 & $40 \%$ \\
\hline $\mathrm{Ba}(\mathrm{ppm})$ & 503 & $45 \%$ & 503 & $29 \%$ & 487 & $24 \%$ \\
\hline $\mathrm{Co}(\mathrm{ppm})$ & 23 & $72 \%$ & 22 & $47 \%$ & 22 & $38 \%$ \\
\hline $\mathrm{Cr}(\mathrm{ppm})$ & 85 & $58 \%$ & 83 & $33 \%$ & 81 & $25 \%$ \\
\hline $\mathrm{Cu}(\mathrm{ppm})$ & 46 & $82 \%$ & 43 & $53 \%$ & 44 & $49 \%$ \\
\hline $\mathrm{F}(\mathrm{ppm})$ & 452 & $50 \%$ & 457 & $32 \%$ & 460 & $28 \%$ \\
\hline $\mathrm{Nb}(\mathrm{ppm})$ & 27 & $59 \%$ & 27 & $37 \%$ & 29 & $30 \%$ \\
\hline $\mathrm{Ni}(\mathrm{ppm})$ & 34 & 53 & 33 & $36 \%$ & 34 & $30 \%$ \\
\hline $\mathrm{Pb}(\mathrm{ppm})$ & 38 & 255 & 32 & $70 \%$ & 30 & $49 \%$ \\
\hline $\mathrm{Sr}(\mathrm{ppm})$ & 59 & 82 & 59 & $57 \%$ & 63 & $43 \%$ \\
\hline $\mathrm{V}(\mathrm{ppm})$ & 108 & 50 & 105 & $30 \%$ & 106 & $34 \%$ \\
\hline $\mathrm{Y}(\mathrm{ppm})$ & 30 & 61 & 30 & $35 \%$ & 30 & $23 \%$ \\
\hline $\mathrm{Zn}(\mathrm{ppm})$ & 89 & 65 & 87 & $37 \%$ & 86 & $29 \%$ \\
\hline $\mathrm{Zr}(\mathrm{ppm})$ & 290 & 86 & 286 & $46 \%$ & 287 & $33 \%$ \\
\hline & & & & & & \\
\hline
\end{tabular}

Tabela 3 - Coeficientes de correlação de Spearman para os dados geoquímicos sem transformação, expressos no intervalo 0-10 para as microbacias A (sombreamento cinza, acima da diagonal) e as microbacias B (sem sombreamento, abaixo da diagonal).

\begin{tabular}{l|ccccccccccccccccccc}
\hline & $\mathrm{Fe}$ & $\mathrm{Ca}$ & $\mathrm{Mg}$ & $\mathrm{Ti}$ & $\mathrm{Mn}$ & $\mathrm{As}$ & $\mathrm{Ba}$ & $\mathrm{Co}$ & $\mathrm{Cr}$ & $\mathrm{Cu}$ & $\mathrm{F}$ & $\mathrm{Nb}$ & $\mathrm{Ni}$ & $\mathrm{Pb}$ & $\mathrm{Sr}$ & $\mathrm{V}$ & $\mathrm{Y}$ & $\mathrm{Zn}$ & $\mathrm{Zr}$ \\
\hline $\mathrm{Fe}$ & 10 & $*$ & $*$ & 6 & 9 & 7 & $*$ & 8 & 5 & 9 & 4 & $*$ & 8 & 7 & $*$ & 7 & 5 & 7 & $*$ \\
$\mathrm{Ca}$ & $*$ & 10 & 6 & $*$ & $*$ & $*$ & $*$ & $*$ & $*$ & $*$ & $*$ & $*$ & $*$ & $*$ & $*$ & $*$ & $*$ & $*$ & $*$ \\
$\mathrm{Mg}$ & $*$ & 6 & 10 & $*$ & $*$ & $*$ & 4 & $*$ & 4 & 4 & $*$ & $*$ & 5 & $*$ & $*$ & 5 & $*$ & 4 & $*$ \\
$\mathrm{Ti}$ & 6 & $*$ & $*$ & 10 & 4 & $*$ & $*$ & 5 & 4 & 5 & $*$ & 7 & 5 & $*$ & $*$ & 6 & $*$ & $*$ & $*$ \\
$\mathrm{Mn}$ & 9 & $*$ & $*$ & 5 & 10 & 7 & 4 & 8 & 5 & 8 & 4 & $*$ & 7 & 8 & $*$ & 6 & 4 & 7 & $*$ \\
$\mathrm{As}$ & 7 & $*$ & $*$ & $*$ & 6 & 10 & $*$ & 5 & 5 & 6 & 5 & $*$ & 6 & 7 & $*$ & 5 & $*$ & 6 & $*$ \\
$\mathrm{Ba}$ & $*$ & $*$ & 5 & $*$ & $*$ & $*$ & 10 & $*$ & $*$ & $*$ & $*$ & $*$ & $*$ & 5 & $*$ & $*$ & 6 & 4 & 4 \\
$\mathrm{Co}$ & 8 & $*$ & $*$ & 6 & 8 & 5 & $*$ & 10 & 5 & 8 & 4 & $*$ & 8 & 7 & $*$ & 7 & 5 & 6 & $*$ \\
$\mathrm{Cr}$ & 6 & $*$ & $*$ & 4 & 5 & 5 & 4 & 6 & 10 & 5 & $*$ & $*$ & 5 & 5 & $*$ & 6 & 4 & $*$ & $*$ \\
$\mathrm{Cu}$ & 8 & $*$ & $*$ & 7 & 8 & 6 & $*$ & 8 & 5 & 10 & 4 & $*$ & 8 & 7 & $*$ & 7 & 4 & 7 & $*$ \\
$\mathrm{~F}$ & $*$ & $*$ & $*$ & $*$ & $*$ & 5 & $*$ & $*$ & $*$ & $*$ & 10 & $*$ & 4 & $*$ & $*$ & $*$ & $*$ & $*$ & $*$ \\
$\mathrm{Nb}$ & $*$ & $*$ & $*$ & 7 & $*$ & $*$ & $*$ & 5 & $*$ & 4 & $*$ & 10 & $*$ & $*$ & $*$ & $*$ & $*$ & $*$ & $*$ \\
$\mathrm{Ni}$ & 8 & $*$ & $*$ & 5 & 6 & 6 & $*$ & 8 & 6 & 8 & 5 & $*$ & 10 & 6 & $*$ & 7 & 5 & 7 & $*$ \\
$\mathrm{~Pb}$ & 7 & $*$ & $*$ & 4 & 7 & 7 & $*$ & 7 & 5 & 7 & 4 & $*$ & 6 & 10 & $*$ & 5 & 6 & 6 & $*$ \\
$\mathrm{Sr}$ & $*$ & $*$ & $*$ & $*$ & $*$ & $*$ & $*$ & $*$ & $*$ & $*$ & $*$ & $*$ & $*$ & $*$ & 10 & $*$ & $*$ & $*$ & 4 \\
$\mathrm{~V}$ & 8 & $*$ & 4 & 6 & 7 & 5 & $*$ & 7 & 6 & 7 & $*$ & $*$ & 7 & 5 & $*$ & 10 & $*$ & 6 & $*$ \\
$\mathrm{Y}$ & 5 & $*$ & $*$ & $*$ & $*$ & 4 & 5 & 5 & 4 & 4 & 4 & $*$ & 5 & 5 & 4 & $*$ & 10 & 4 & $*$ \\
$\mathrm{Zn}$ & 7 & $*$ & $*$ & $*$ & 6 & 5 & $*$ & 6 & $*$ & 6 & 4 & $*$ & 7 & 6 & $*$ & 6 & $*$ & 10 & $*$ \\
$\mathrm{Zr}$ & $*$ & $*$ & $*$ & $*$ & $*$ & $*$ & 6 & $*$ & $*$ & $*$ & $*$ & $*$ & $*$ & $*$ & 4 & $*$ & $*$ & $*$ & 10 \\
\hline
\end{tabular}



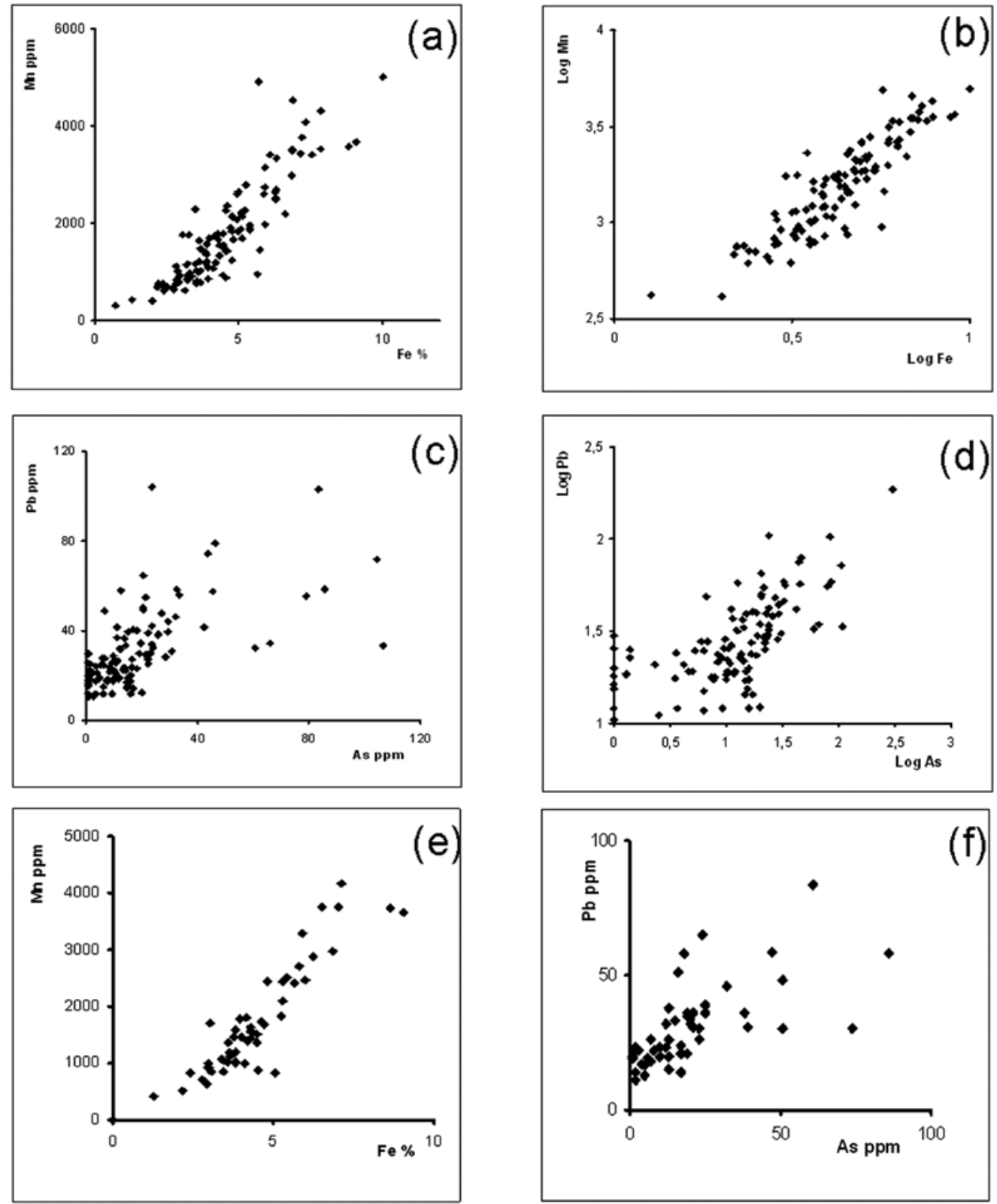

Figura 3 - Diagramas de dispersão para as microbacias A: (a) $\mathrm{Fe}-\mathrm{Mn}$; (b) $\mathrm{Fe}-\mathrm{Mn}$ em logs; (c) As - Pb; (d) As-Pb em logs; e para as microbacias B (e) Fe-Mn e (f) As-Pb.

no intervalo 0,28 - 0,34 para os elementos $\mathrm{Mg}, \mathrm{Cu}, \mathrm{Ni}$ e F. Situação semelhante foi obtida com a transformação dos dados em logaritmos. Este resultado sugere a influência de outliers ou pelo menos duas subpopulações (classes) no conjunto dos dados.

Na figura 4 é apresentado o diagrama de dispersão área de microbacia vs teor de As para as microbacias A. O diagrama sugere a ocorrência de grupos de amostras com comportamento diferente, que foram denominadas Classes $0,1 \mathrm{e} 2$. A Classe 0 corresponde a uma relação moderada entre a área de microbacia e o teor do elemento, ou seja, o teor aumenta de maneira suave proporcionalmente ao aumento do tamanho da microbacia. Nesse caso, tratam-se de microbacias relacionadas ao fundo regional. Para a Classe 1 a relação entre a área de microbacia e o teor do elemento é mais elevada, ou seja, o teor aumenta rapidamente com o incremento do tamanho das microbacias. Estão inclusas aqui as microbacias relacionadas com mineralizações, porém é difícil caracterizar o fenômeno para baixos teores de As. A Classe 2 representa outliers empobrecidas, enriquecidas ou de transição. A situação foi reiterada para o $\mathrm{Pb}$, porém com maior dispersão, principalmente para a Classe 1. Comportamento semelhante foi verificado para as microbacias B.

AJUSTE DOS MODELOS DE REGRESSÃO O processamento estatístico exploratório sugere que diferentes processos geológicos controlam a variabilidade geoquímica, como o conteúdo de óxidos de $\mathrm{Fe}$, a erosão e a ocorrência de rochas específicas ou mineralizações. Isso é verificado em função da correlação de vários ele- 
mentos traço com o teor de Fe (Tab. 3), os diagramas de dispersão (Fig. 3) e a relação da área das microbacias A com o teor de As (Fig. 4). O mesmo é observado para as microbacias $\mathrm{B}$ e para o $\mathrm{Pb}$. Assim, assumiu-se que os teores de $\mathrm{As}$ e de $\mathrm{Pb}$ nos sedimentos de corrente podem ser reproduzidos por uma combinação linear de variáveis físicas e químicas (modelo de regressão).

$\mathrm{O}$ ajuste do modelo envolveu algumas decisões prévias, como a aplicação de transformações e o número e tipo de variáveis envolvidas, sendo realizado de maneira iterativa. As classes 0 e 1 foram consideradas de maneira independente.

Cada linha da tabela 4 representa um modelo de regressão, segundo a equação (1). Para obter o teor de As calculado, os valores das colunas com nome de elemento químico ( $\mathrm{Fe}, \mathrm{Mn}, \mathrm{Cu}$ e $\mathrm{Pb}$ no caso), devem ser multiplicados pelo teor da variável correspondente e somados, incluindo a constante $(\mathrm{K})$, que é multiplicada pelo valor 1. Os modelos 4B (equação 2) e 4C (equação 3) apresentaram os melhores parâmetros de ajuste, ou seja VEX e $\mathrm{F}$ mais elevados, representando maior variância explicada e menor influência da variância residual, respectivamente.

$$
\begin{aligned}
& (\mathrm{As})_{\text {Classe } 0}=1,6(\mathrm{Fe})+0,08(\mathrm{~Pb})+0,74(\text { Área })-6,4 \\
& (\mathrm{As})_{\text {Classe } 0}=1,4(\mathrm{Fe})+0,001(\mathrm{Mn})+0,76(\text { Área })-5,3
\end{aligned}
$$

A variabilidade do As foi explicada pelo teor de $\mathrm{Fe}$, pelo teor de $\mathrm{Pb}$ de maneira secundária e pela área de microbacia (eq. 2), sendo o $\mathrm{Pb}$ substituído pelo $\mathrm{Mn}$ para o modelo $4 \mathrm{C}$ (eq. 3). Os outros modelos podem ser descartados devido ao coeficiente negativo para o $\mathrm{Cu}$ ou a baixa variância explicada. Os coeficientes de correlação de Spearman do As com essas variáveis (Classe 0 ) variaram no intervalo $0,49-0,71$.

$\mathrm{O}$ descarte dos modelos com coeficientes negativos é justificado pela não observação de correlações negativas em função dos diagramas de dispersão. Do ponto de vista teórico, a área de microbacia e a declividade estão relacionadas à erosão, enquanto que o teor de Fe vincula-se aos fenômenos de adsorção de elementos traços ou à ocorrência de rochas máficas ou mineralizações. Assim, coeficientes positivos são previstos para um modelo de regressão linear envolvendo essas variáveis.

Em contraste com a situação anterior, os modelos de regressão do As para as microbacias A da Classe 1 apresentaram melhor ajuste para os dados log-transformados (Tab. 5). Os modelos 5E, 5G e 5H foram selecionados em função dos valores de $V E X$ e $F$, apresentando participação diferenciada de $\mathrm{Cr}, \mathrm{Pb}, \mathrm{V}$ e $\mathrm{a}$ área de microbacias. Os coeficientes de correlação de Spearman do As com essas variáveis (Classe 1) variaram no intervalo $0,54-0,72$.

Os modelos de regressão do $\mathrm{Pb}$ para as microbacias A apresentaram baixa variância explicada pelo modelo, em particular para a classe 1 (Tab. 6). Para a classe 0 , os modelos $6 \mathrm{~A}, 6 \mathrm{D}$ e $6 \mathrm{~F}$ apresentaram os melhores parâmetros de ajuste, muito embora o valor de VEX foi moderado. Para as microbacias B, os modelos

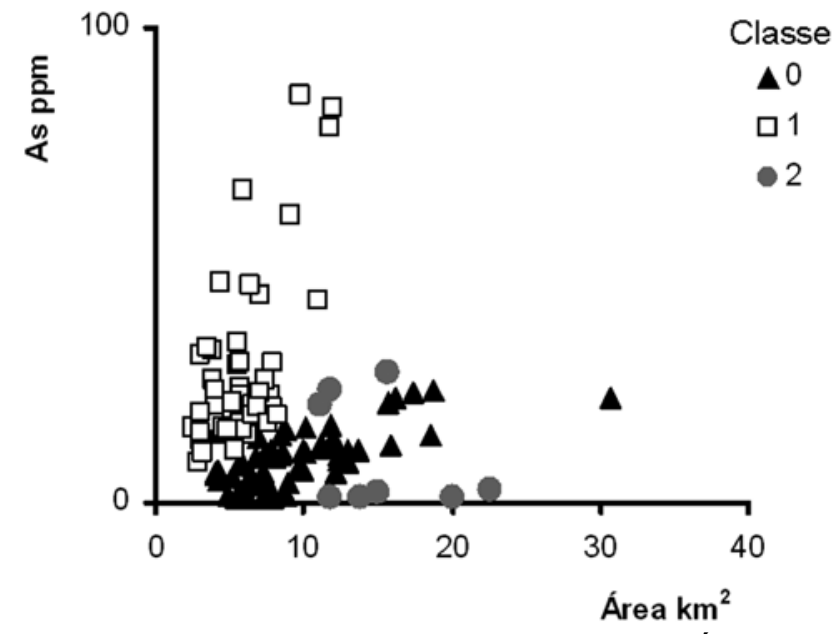

Figura 4 - Diagrama de dispersão Área Teor de As para as microbacias A (um outlier com 298 ppm de As não aparece na figura).

Tabela 4 - Modelos de regressão para As, considerando as 55 microbacias A da Classe 0. VEX = Variância Explicada pelo modelo. " $L$ " refere-se à aplicação da transformação logarítmica (S) ou não transformação (N).

\begin{tabular}{c|ccccccccc}
\hline Modelo & VEX & $\mathrm{L}$ & $\mathrm{Fe}$ & $\mathrm{Mn}$ & $\mathrm{Cu}$ & $\mathrm{Pb}$ & Área & $\mathrm{K}$ & $\mathrm{F}$ \\
\hline 4A & $70 \%$ & $\mathrm{~N}$ & 1,9 & Não & $-0,04$ & 0,08 & 0,74 & $-6,5$ & 30 \\
4B & $70 \%$ & $\mathrm{~N}$ & 1,6 & Não & Não & 0,08 & 0,74 & $-6,4$ & 40 \\
4C & $70 \%$ & $\mathrm{~N}$ & 1,4 & 0,001 & Não & Não & 0,76 & $-5,3$ & 39 \\
4D & $69 \%$ & $\mathrm{~N}$ & 2,2 & Não & $-0,03$ & Não & 0,75 & $-5,9$ & 38 \\
4F & $57 \%$ & $\mathrm{~S}$ & 1,2 & Não & Não & 0,09 & 0,82 & $-8,0$ & 22 \\
\hline
\end{tabular}

Tabela 5 - Modelos de regressão para As, considerando as 46 microbacias A da Classe 1. VEX = Variância Explicada pelo modelo. " $L$ " refere-se à aplicação da transformação logarítmica (S) ou não transformação (N).

\begin{tabular}{c|ccccccccc}
\hline Modelo & VEX & L & Fe & Cr & Pb & V & Área & K & F \\
\hline $5 \mathrm{~A}$ & $58 \%$ & $\mathrm{~N}$ & $-1,3$ & 0,36 & 0,24 & Não & 4,3 & $-29,0$ & 15 \\
$5 \mathrm{~B}$ & $61 \%$ & $\mathrm{~N}$ & Não & 0,14 & 0,19 & 0,21 & 4,0 & $-35,1$ & 17 \\
$5 \mathrm{C}$ & $58 \%$ & $\mathrm{~N}$ & Não & 0,31 & 0,21 & Não & 4,4 & $-30,5$ & 20 \\
$5 \mathrm{D}$ & $60 \%$ & $\mathrm{~N}$ & Não & Não & 0,23 & 0,28 & 4,1 & $-31,9$ & 22 \\
$5 \mathrm{E}$ & $65 \%$ & $\mathrm{~S}$ & Não & Não & 0,37 & 0,78 & 0,60 & $-4,8$ & 27 \\
$5 \mathrm{~F}$ & $64 \%$ & $\mathrm{~S}$ & Não & 0,75 & Não & 0,64 & 0,60 & $-5,4$ & 25 \\
$5 \mathrm{G}$ & $66 \%$ & $\mathrm{~S}$ & Não & 0,81 & 0,35 & $\mathrm{Não}$ & 0,62 & $-4,9$ & 27 \\
$5 \mathrm{H}$ & $68 \%$ & $\mathrm{~S}$ & Não & 0,53 & 0,30 & 0,49 & 0,58 & $-5,0$ & 22 \\
$5 \mathrm{I}$ & $70 \%$ & $\mathrm{~S}$ & $-0,46$ & 0,60 & 0,40 & 0,78 & 0,52 & $-4,2$ & 18 \\
\hline
\end{tabular}

de regressão do As mostraram boa concordância com os anteriores (Tab. 7), sendo os modelos aprimorados no caso do $\mathrm{Pb}$ (Tab. 8).

$\mathrm{Na}$ figura 5 foram disponibilizados, espacial- 
Tabela 6 - Modelos de regressão para o Pb, considerando as microbacias A (69 espécimes para a classe 0 e 32 para a classe 1). $C=$ Classe; VEX = Variância Explicada pelo modelo; $D E C=$ Declividade. " $L$ " refere-se à aplicação da transformação logarítmica (S) ou não transformação $(N)$.

\begin{tabular}{c|c|c|c|c|c|c|c|c|c|c|c|c}
\hline Modelo & $\mathrm{C}$ & VEX & $\mathrm{L}$ & $\mathrm{Fe}$ & $\mathrm{Mn}$ & $\mathrm{As}$ & $\mathrm{Ni}$ & $\mathrm{Zn}$ & Área & DEC & $\mathrm{K}$ & $\mathrm{F}$ \\
6A & 0 & $57 \%$ & $\mathrm{~N}$ & 0,68 & 0,006 & Não & Não & Não & 0,31 & Não & 9,3 & 29 \\
6B & 0 & $51 \%$ & $\mathrm{~S}$ & 0,04 & 0,40 & Não & Não & Não & 0,10 & Não & $-0,71$ & 23 \\
6C & 0 & $49 \%$ & $\mathrm{~N}$ & 3,0 & Não & 0,13 & Não & Não & 0,34 & Não & 6,3 & 21 \\
6D & 0 & $55 \%$ & $\mathrm{~N}$ & 0,99 & 0,006 & Não & Não & Não & Não & Não & 10,4 & 40 \\
6E & 0 & $57 \%$ & $\mathrm{~N}$ & Não & 0,006 & 0,03 & Não & Não & 0,33 & Não & 10,4 & 28 \\
6F & 0 & $53 \%$ & $\mathrm{~S}$ & Não & 0,50 & $-0,06$ & Não & Não & 0,10 & Não & $-0,81$ & 24 \\
6G & 1 & $34 \%$ & $\mathrm{~S}$ & Não & Não & Não & 0,26 & 0,33 & Não & 0,96 & $-0,60$ & 5 \\
6H & 1 & $25 \%$ & $\mathrm{~S}$ & $-0,01$ & Não & Não & Não & 0,56 & Não & Não & 0,59 & 5 \\
6I & 1 & $27 \%$ & $\mathrm{~N}$ & Não & 0,03 & 0,22 & Não & Não & Não & 5,1 & $-54,8$ & 4 \\
6J & 1 & $28 \%$ & $\mathrm{~S}$ & Não & 0,21 & 0,15 & Não & Não & Não & 1,3 & $-0,92$ & 4 \\
\hline
\end{tabular}

Tabela 7 - Modelos de regressão para o As, considerando as microbacias $B$ (13 espécimes para a classe 0 e 30 espécimes para a classe 1). $C=$ Classe; VEX = Variância Explicada pelo modelo. " $L$ " refere-se à aplicação da transformação logarítmica (S) ou não transformação $(N)$.

\begin{tabular}{c|c|c|c|c|c|c|c|c|c|c|c}
\hline Modelo & C & VEX & L & Fe & Cr & Cu & Pb & V & Área & K & F \\
\hline 7A & 0 & $97 \%$ & N & 0,19 & $-0,03$ & 0,05 & 0,26 & Não & 0,44 & $-18,5$ & 42 \\
7B & 0 & $97 \%$ & N & $-0,06$ & Não & 0,06 & 0,22 & Não & 0,45 & $-20,2$ & 57 \\
7C & 0 & $97 \%$ & N & 0,32 & Não & Não & 0,24 & Não & 0,46 & $-20,7$ & 83 \\
7D & 1 & $81 \%$ & N & Não & 0,28 & Não & 0,13 & $-0,03$ & 0,91 & $-29,0$ & 27 \\
7E & 1 & $81 \%$ & N & Não & 0,25 & Não & 0,13 & Não & 0,92 & $-30,4$ & 37 \\
7H & 1 & $81 \%$ & N & $-0,80$ & 0,28 & Não & 0,14 & Não & 0,92 & $-29,4$ & 27 \\
7I & 1 & $68 \%$ & S & Não & 1,00 & Não & 0,47 & Não & 1,10 & $-9,6$ & 19 \\
\hline
\end{tabular}

Tabela 8 - Modelos de regressão para o $\mathrm{Pb}$, considerando as microbacias $B$ (30 espécimes para a classe 0 e 12 espécimes para a classe 1). C = Classe; VEX = Variância Explicada pelo modelo; $D E C=$ Declividade.

\begin{tabular}{c|c|c|c|c|c|c|c|c|c|c|c}
\hline Modelo & C & VEX & Fe & Mn & As & Co & Zn & Área & DEC & K & F \\
\hline $8 \mathrm{~A}$ & 0 & $73 \%$ & 0,02 & 0,04 & 0,11 & Não & 0,50 & 0,90 & Não & 8,5 & 17 \\
$8 \mathrm{~B}$ & 0 & $71 \%$ & 2,19 & Não & 0,12 & Não & Não & 0,22 & Não & 5,0 & 21 \\
$8 \mathrm{C}$ & 0 & $73 \%$ & Não & 0,04 & 0,11 & Não & Não & 0,19 & Não & 8,6 & 23 \\
$8 \mathrm{D}$ & 1 & $82 \%$ & Não & Não & 0,15 & $-0,40$ & 0,50 & 0,90 & 2,5 & $-56,1$ & 5 \\
$8 \mathrm{E}$ & 1 & $60 \%$ & Não & Não & Não & 0,46 & 0,44 & Não & 3,3 & $-66,5$ & 4 \\
$8 \mathrm{~F}$ & 1 & $76 \%$ & Não & Não & $-0,03$ & Não & 0,50 & 0,92 & Não & $-17,7$ & 8 \\
$8 \mathrm{G}$ & 1 & $76 \%$ & Não & $-0,001$ & Não & Não & 0,50 & 0,93 & Não & $-17,4$ & 8 \\
$8 \mathrm{H}$ & 1 & $81 \%$ & Não & Não & Não & $-0,22$ & 0,56 & 0,90 & 2,1 & $-54,5$ & 7 \\
$8 \mathrm{I}$ & 1 & $77 \%$ & Não & Não & Não & $-0,27$ & 0,55 & 1,00 & Não & $-17,6$ & 9 \\
$8 \mathrm{~J}$ & 1 & $76 \%$ & Não & Não & Não & Não & 0,48 & 0,92 & Não & $-16,5$ & 14 \\
$8 \mathrm{~K}$ & 1 & $75 \%$ & Não & Não & Não & Não & 0,57 & Não & 3,4 & $-68,5$ & 6 \\
\hline
\end{tabular}

mente, os dados geoquímicos do As para as microbacias A. A sobreposição entre as ocorrências minerais e as anomalias de As em sedimentos de corrente não é ideal, mas, sem dúvida, existe uma correlação espacial entre ambas. As microbacias da classe 1 também parecem acompanhar os teores elevados de As. Algumas microbacias da classe 2 (outliers) apresentaram empobrecimento de As. As microbacias com menos de 3 amostras de sedimentos de corrente no seu interior foram descartadas do processamento e não foram delineadas. $\mathrm{Na}$ figura 6 é apresentada a distribuição dos dados geoquímicos do $\mathrm{Pb}$ para as microbacias B. Destaca-se que a mina Furnas foi incluída nas microbacias da classe $1 \mathrm{e}$ que a microbacia a Leste de Iporanga foi considerada classe 0 , apesar de possuir teores moderados de $\mathrm{Pb}$.

\section{DISCRIMINAÇÃO DE POSSÍVEL ASSINATURA GEOQUÍMICA ANTRÓPICA O diagramas de dis-} persão área $v s \mathrm{As}$ ou $\mathrm{Pb}$ sugerem a existência de grupos de amostras com comportamento específico, identificados como classes $0,1 \mathrm{e} 2$. Essas classes correspondem ao fundo regional, ao fundo local (mineralizações, Unidade Piririca) e às outliers, sendo associadas aos fenômenos naturais que controlam a variância geoquímica, ou seja, erosão, litotipos e mineralizações. A influência antrópica não foi representada nos modelos de regressão, pois trata-se de um fenômeno local (mina Furnas), visto que o restante da área não tem sido explorada de maneira intensiva (Moraes 1997). Assim, a comparação do teor avaliado pelos modelos com a resposta real, poderá representar um indicativo da mencionada ação antrópica. A geoquímica de sedimentos de corrente mostrou assinatura característica para $\mathrm{As}$ e $\mathrm{Pb}$ nas proximidades da mina (Figs. 5 e 6). Porém as microbacias A ao redor da mina não foram consideradas no processamento estatístico exploratório, nem nos modelos de regressão. Isso pois foram descartadas as microbacias com menos de três amostras no seu interior. Assim, com o intuito de se avaliar a influência da atividade mineradora na resposta geoquímica, foi introduzida no conjunto de dados a microbacia 95, localizada muito próxima da mina Furnas e que contem somente duas amostras, ambas anômalas para $\mathrm{As}, \mathrm{Pb}$ e $\mathrm{Zn}$.

Foram calculados os valores de As para os modelos mais adequados, discriminados em função da classe 0 (Tab. 6) e da classe 1 (Tab. 7), sendo representados junto aos teores reais de As (Fig. 7). O modelo da classe 1 também foi aplicado sobre as microbacias da classe 2 (outliers). A microbacia 95 mostrou-se bastante afastada do modelo teórico (linha pontilhada), da mesma forma que uma microbacia da classe 2 (a microbacia 109) e uma microbacia da classe 1 (a microbacia 44).

Ao representar a diferença $\left(\mathrm{As}_{\text {real }}-\mathrm{As}_{\text {calculado }}\right)$ espacialmente, observa-se que os valores calculados pelo modelo são muito próximos aos reais, com exceção de algumas microbacias, que apresentaram forte afastamento do modelo (Fig. 8). Destaca-se que as microbacias que apresentaram diferenças negativas foram anuladas, pois apresentaram baixos teores de As (1- $42 \mathrm{ppm}$ ). A assinatura geoquímica das microbacias 44, 95, 109 e 136 


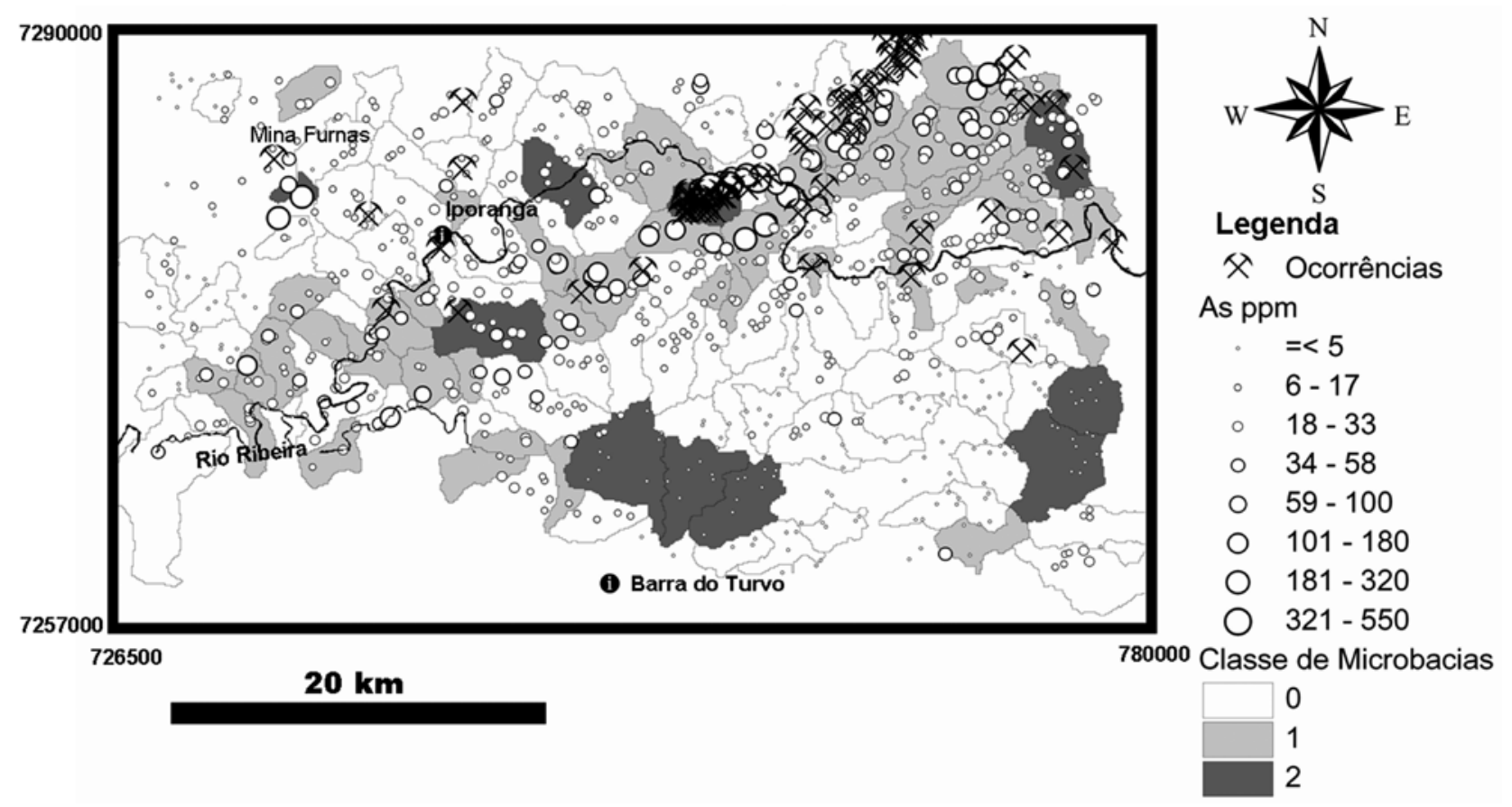

Figura 5 - Espacialização das microbacias A (geoquímica do As). Coordenadas em Projeção UTM, região Sul 22, Datum Córrego Alegre.

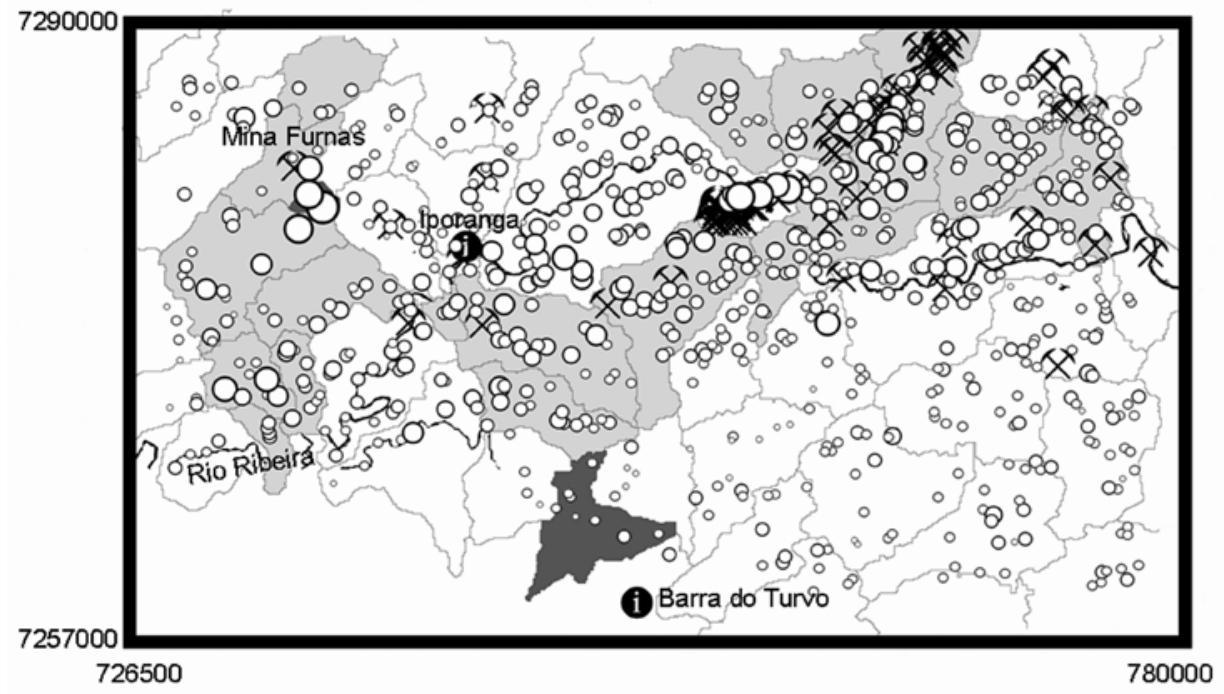

$20 \mathbf{~ k m}$

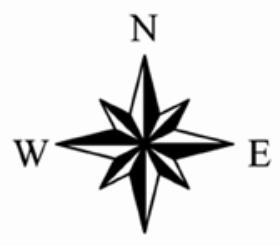

$\mathrm{S}$

Legenda

父 Ocorrências

$\mathrm{Pb}$ ppm

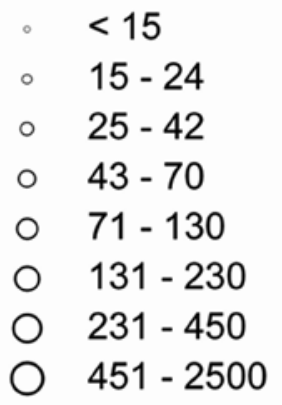

Classe de Microbacias

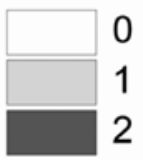

Figura 6 - Espacialização das microbacias B (geoquímica do Pb). Coordenadas em Projeção UTM, região Sul 22, Datum Córrego Alegre.

(Fig. 8), todas com forte desvio do modelo para o As, foram comparadas com as medianas de quatro amostras anômalas próximas à mina Furnas (assinatura geoquími- ca local). A resposta da microbacia 95 é diferenciada e semelhante à da resposta local na mina Furnas (Fig. 9), ressaltando-se o enriquecimento em $\mathrm{Pb}$ e $\mathrm{Zn}$ (menor teor 


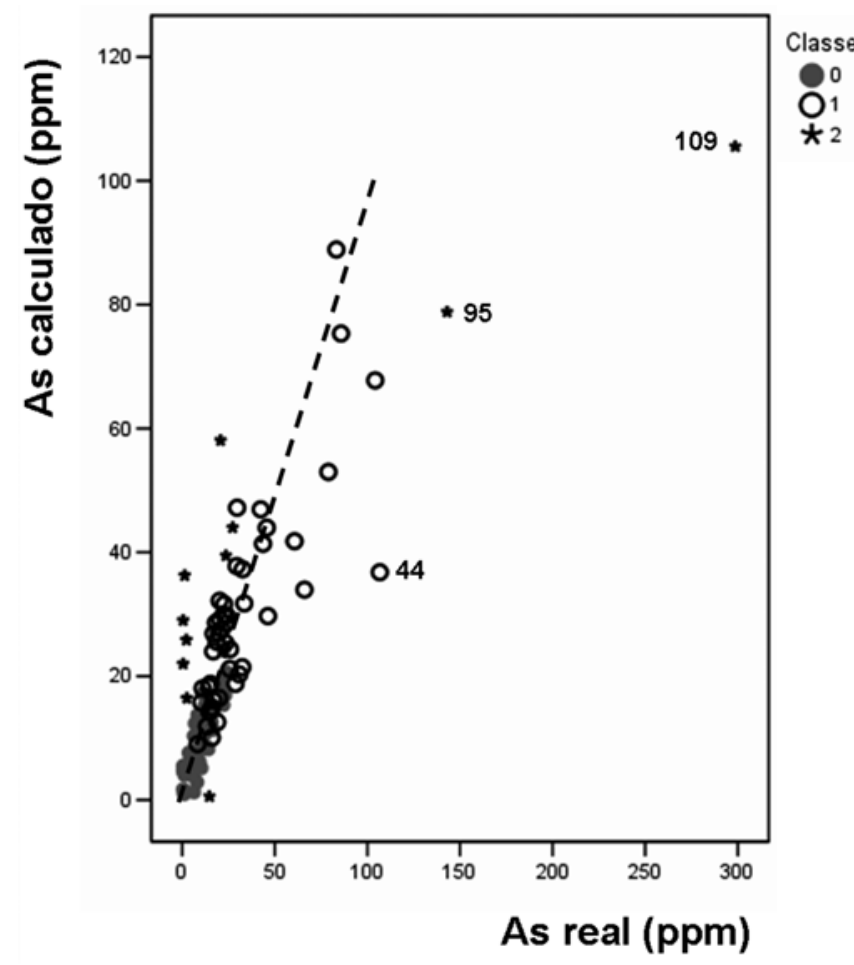

Figura 7 - Diagrama de dispersão As - As para as microbacias $A$.

de As). A microbacia 44 (Classe 1) localizada a nordeste da figura 8 , apresenta uma assinatura geoquímica semelhante a da microbacia136 (teores de Mn, Cr, V e Zn moderados e baixos teores de $\mathrm{As}$ e $\mathrm{Pb}$ ), sendo possivelmente associadas a rochas máficas. A microbacia 109 (outlier), localizada aproximadamente no centro da figura 8 , apresenta assinatura geoquímica concordante com a Unidade "Piririca", teor elevado de As e menor de $\mathrm{Pb}$.

As microbacias B não foram usadas para caracterizar a influência da atividade humana sobre a assinatura geoquímica (fenômeno local), por estarem associadas a fenômenos regionais.

DISCUSSÃO Os resultados apresentados servem como orientação para discutir a aplicação do método das microbacias. Em relação à normalidade das distribuições, ao aumentar o tamanho das microbacias houve um melhor ajuste ao comportamento normal, como era previsto em função do Teorema do Limite Central. Os coeficientes de variação mostraram uma atenuação da variabilidade geoquímica com o aumento do tamanho das microbacias, sendo reduzido o efeito das outliers e, em conseqüência, aprimorada a resposta dos métodos estatísticos multivariados. Por outro lado, as microbacias A se sobrepuseram de maneira mais precisa sobre as anomalias/ocorrências de As (Figs. 5 e 6).

A análise das dependências (Tab. 3) mostrou que o Fe controlou grande parte da variância geoquímica, com vários elementos associados $(\mathrm{Ti}, \mathrm{Mn}, \mathrm{Co}, \mathrm{Cr}$, $\mathrm{Cu}, \mathrm{Ni}, \mathrm{V}, \mathrm{Y}, \mathrm{As}, \mathrm{Pb}$ e $\mathrm{Zn}$ ). Isso sugere a possibilidade de que duas espécies minerais controlam a variância geoquímica em escala regional - uma relacionada aos óxidos de $\mathrm{Fe}-(\mathrm{Mn}$ ?) e outra aos minerais máficos que ocorrem na área, como piroxênio, anfibólio e biotita.

Os modelos de regressão foram calculados para as classes 0 e 1 considerando os dois conjuntos de microbacias. Para as microbacias A da classe 0, o As mostrou-se relacionado ao $\mathrm{Fe}$, ao $\mathrm{Pb}$ e a área de microbacia (Tab. 4). Para a classe $1, \mathrm{Cr}$ e V substituíram o Fe (Tab. 5). Para as microbacias B, o V foi eliminado do segundo modelo, o que foi interpretado como perda da influência das variações locais. Do ponto de vista geoquímico, esses modelos podem ser explicados em termos da influência de minerais de Ferro ( $\mathrm{Fe}$ ), de minerais máficos $(\mathrm{Cr}-\mathrm{V})$, das mineralizações de sulfetos $(\mathrm{Pb})$ e dos processos de erosão (área). A troca do $\mathrm{Fe}$ pelo $\mathrm{Cr}-(\mathrm{V})$ ao passar da classe 0 para a classe 1 , sugere a presença de duas espécies mineralógicas diferentes agindo em cada classe (e.g., óxidos de $\mathrm{Fe}$ e minerais máficos). A presença do $\mathrm{Pb}$ em ambos os casos (microbacias A e B) demonstra uma correlação entre As $\mathrm{e} \mathrm{Pb}$, que verifica-se para o background geoquímico e também para as mineralizações. A participação dos óxidos de $\mathrm{Fe}$ nos processos exógenos de retenção do As no Vale do Ribeira e a relação da área das microbacias com a mobilidade dos elementos químicos no ambiente, são fenômenos reconhecidos por diversos pesquisadores (Morgental et al. 1978; Hawkes 1976).

Os modelos de regressão para o $\mathrm{Pb}$ mostraram uma associação com $\mathrm{Mn}, \mathrm{Fe}$ ou As e a área de microbacia para a classe 0 . Para a classe 1 , as microbacias B mostraram uma associação com Zn e a área. Essas associações sugerem um comportamento geoquímico diferenciado para o $\mathrm{Pb}$, com uma fase mineralógica (óxidos de $\mathrm{Fe}-\mathrm{Mn}$ ?) controlando a sua variabilidade a nível regional. A possível substituição do Fe pelo As ainda não é bem compreendida, mas pode ser conseqüência da forte correlação entre ambos os elementos. Para as mineralizações, o $\mathrm{Zn}$ ocorre intimamente associado ao $\mathrm{Pb}$, como acontece na mina Furnas.

Em relação à influência do homem sobre a assinatura geoquímica, a microbacia 95 apresentou resposta peculiar, isolada e semelhante ao padrão local em Furnas. A microbacia 136, que mostrou desvio do modelo para o As e se localiza muito próxima da microbacia 95 (Fig. 8), possui baixo contraste, semelhante à microbacia 44 (maior teor de As). A microbacia 109, afetada pela ocorrência de mineralizações, possui alto teor de As e se diferencia da resposta da microbacia 95 , principalmente pelos teores de $\mathrm{Pb}$ e $\mathrm{Zn}$. Observa-se ainda, que quando consideradas as medianas locais em Furnas, menos afetadas por valores extremos que a microbacia 95, os teores de $\mathrm{Pb}$ e $\mathrm{Zn}$ permanecem extremamente elevados em relação as microbacias características da região. Ambos elementos encontram-se enriquecidos no minério explorado em Furnas (Morgental et al. 1978). Isso sugere que a assinatura geoquímica peculiar nesse local, diferente daquela observada em outras microbacias da região, é influenciada pelas atividades mineradoras do passado.

Em concordância com os trabalhos mencionados inicialmente (Selinus \& Esbensen 1995; Korre 1999a,b), os resultados obtidos neste estudo sugerem 


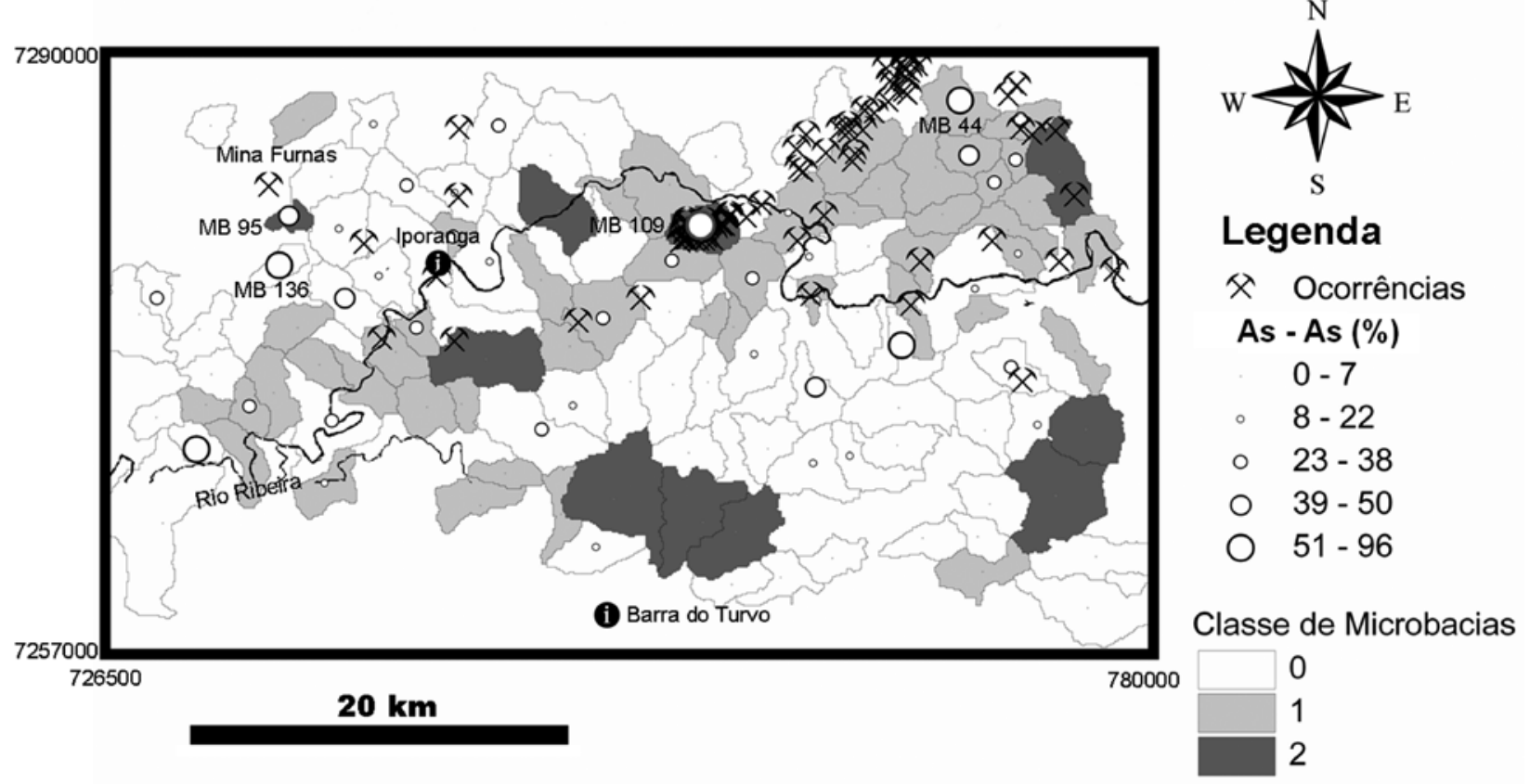

Figura 8 - Espacialização dos teores de As comparando o valor calculado pelo modelo de regressão (As ) com o valor real (As, ) para as microbacias $A$. As - As $=100\left(A s_{r}-A s\right) / A s_{r}$ Os valores negativos foram anulados (cf. texto) e as microbacias 44, 95, 109 e 136 foram identificadas por apresentarem resposta característica (MB 44, MB 95, MB 109 e MB 136). Coordenadas em Projeção UTM, região Sul 22, Datum Córrego Alegre.
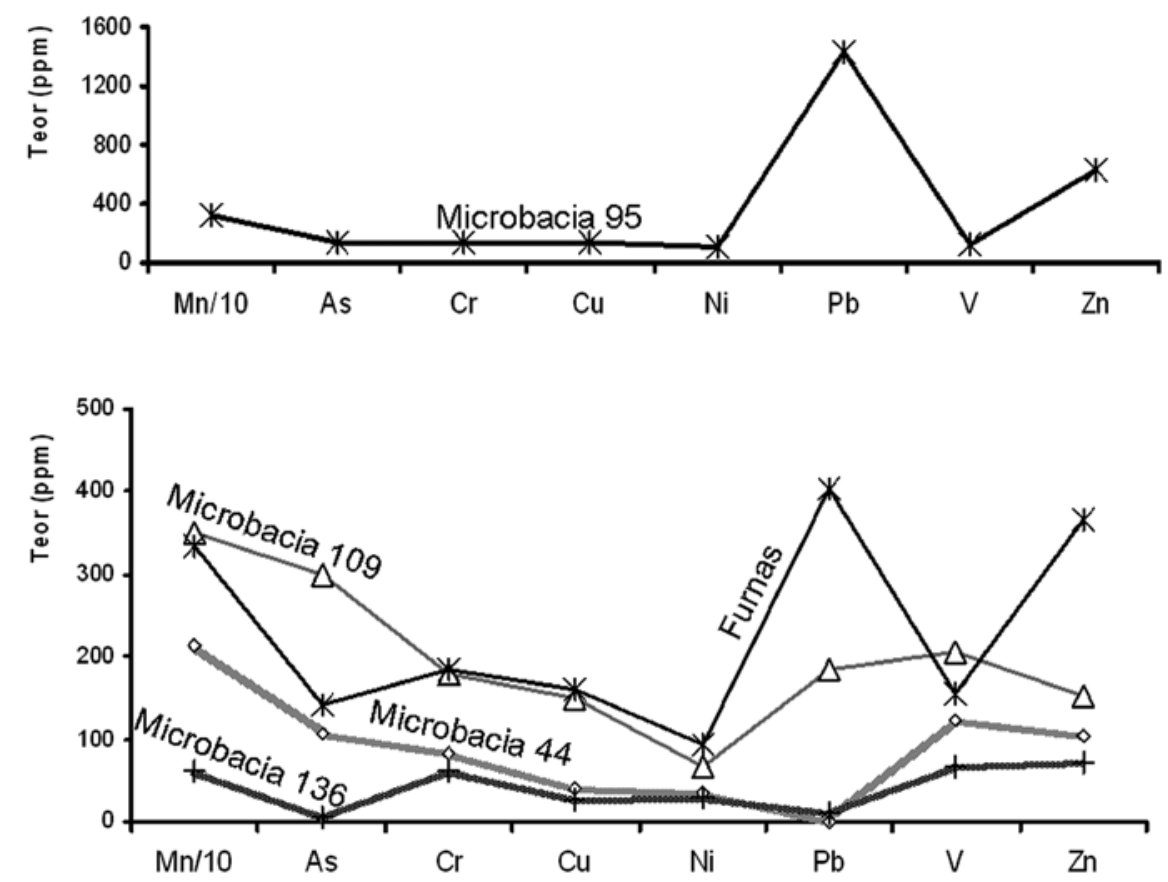

Figura 9 - Comparação da assinatura geoquímica da mina Furnas com microbacias específicas (localização na Fig. 8).

que os métodos estatísticos multivariados representam uma alternativa válida para discriminar a assinatura geoquímica antrópica da assinatura derivada de processos geológicos naturais. No entanto, os dados geoquímicos utilizados foram levantados com enfoque prospectivo, carecendo da rigorosidade que caracteriza aplicações ambientais, principalmente no relativo à precisão analítica. Outro aspecto que poderá ser aprimorado é a rela- 
ção metodologia aplicada vs modelo teórico assumido. Por exemplo, a distribuição heterogênea da amostragem provocou a eliminação de algumas microbacias do processamento estatístico exploratório, em função do escasso número de amostras interiores. Uma amostragem orientada especificamente para o modelo hidrográfico delineado poderá aprimorar os resultados obtidos.

CONCLUSÃO O método das microbacias forneceu um conjunto de dados relativamente homogêneo, menos susceptível aos efeitos das outliers, proporcionando maior confiabilidade aos parâmetros estatísticos avaliados.

Foram caracterizadas diferentes classes dentro do conjunto de microbacias, notadamente as microbacias relacionadas ao background geoquímico regional e aquelas onde ocorrem mineralizações de metais preciosos e de metais base. Essas classes se mantiveram com o incremento do tamanho das microbacias, mas com tendência à eliminação de efeitos de caráter local.
A variável física que melhor se adequou aos procedimentos de modelagem foi à área de microbacia, possivelmente devido a sua maior variabilidade. Os teores de $\mathrm{Fe}, \mathrm{As}, \mathrm{Cr}, \mathrm{Mn}, \mathrm{V}, \mathrm{Pb}$ e $\mathrm{Zn}$ foram as variáveis geoquímicas melhor adaptadas aos modelos de regressão que reproduziram os teores de $\mathrm{As}$ e $\mathrm{Pb}$ para as diversas classes. Isso sugere que fases mineralógicas diferentes, relacionadas à fenômenos supergênicos (área de microbacia, $\mathrm{Fe}$ e $\mathrm{Mn}$ ), à ocorrência de rochas máficas $(\mathrm{Cr}$ e $\mathrm{V})$ ou às mineralizações (As, $\mathrm{Mn}, \mathrm{Pb}$ e $\mathrm{Zn}$ ), controlam a variância geoquímica das microbacias nas diferentes situações.

A análise minuciosa da resposta geoquímica local nos sedimentos de corrente da mina Furnas e sua comparação com a assinatura geoquímica das microbacias características de toda a área de estudo, mostra um comportamento peculiar e diferenciado, com anomalias extremas de $\mathrm{Pb}$ e $\mathrm{Zn}$, sugerindo uma alteração do padrão natural em função das atividades mineradoras exercidas pelo homem no local.

\section{Referências}

Addas W. \& Vinhas C. 1975. Projeto Sudelpa: relatório final de reconhecimento geoquímico. São Paulo, CPRM, vol.15/17.

Beltrame A. 1994. Diagnóstico do meio físico de bacias hidrográficas: modelo e aplicação. Florianópolis, UFSC, 112 p.

Bonham-Carter G. 1994. Geographic Information Sistems for Geocientists: Modelling with GIS. Ottawa, Pergamon, 398p.

Cunha F.G. 2003. Contaminação Humana e Ambiental por Chumbo no Vale do Ribeira, nos Estados de São Paulo e Paraná, Brasil. Tese de Doutoramento, Instituto de Geociências, UNICAMP, 109 p.

Da Silva R. 1997. Geoquímica e impacto ambiental do Arsênio no Vale do Ribeira (SP-PR). Dissertação de Mestrado, Instituto de Geociências, UNICAMP, 100 p.

Davis J. 1986. Statistics and Data Analysis in Geology. New York, Wiley, $646 \mathrm{p}$.

ESRI 1999. ArcGIS (handbook), version 9.1. Redlands, Environmental Systems Research Institute. 4 CD-ROM.

Filippini Alba J., Souza Filho C., Figueiredo B. 2003. Análise de variância de dados geoquímicos assistida por sistemas de informação geográfica: Estudo de caso no Vale do Rbeira. Geoquímica Brasiliensis, 17:48-56.

Gnanadesikan R. \& Kettenring R. 1972. Robust estimates, residuals and outliers detection with multiresponse data. Biometrics, 28:81-124.

Hawkes H.E. 1976. The downstream dilution of stream sediment anomalies. J. Geoch. Exp., 6:345-358.

Joly C.A. 1999. Sinbiota. Disponível em: http://sinbiota.cria.org. br/. Acessado em 19 jan 2010.

Korre A. 1999a. Statistical and spatial assessment of soil heavy metal contamination in areas of poorly recorded, complex sources of pollution. Part 1: Factor Analysis for contamination assessment.Stoch. Envirom. Res. Risk. Ass., 13:260-287.

Korre A. 1999b. Statistical and spatial assessment of soil heavy metal contamination in areas of poorly recorded, complex sources of pollution. Stoch. Envirom. Res. Risk. Ass., 13:288-316.

Moraes R.P. 1997. Transporte de chumbo e metais associados no Rio Ribeira de Iguape, São Paulo, Brasil. Dissertação de
Mestrado, Instituto de Geociências, UNICAMP, 94p.

Morgental A., Batolla Jr. F., Pinto G., Paiva I., Drumond J. 1975. Projeto Sudelpa, relatório final. São Paulo, CPRM.

Morgental A., Silva A.A.G.P. da, Borin Jr. T., Alegri V., Oliveira P.E. 1978. Projeto geoquímica no Vale do Ribeira, relatório final. São Paulo, CPRM, 8 volumes.

Moura P.A. 1997. Potencialidade Mineral da porção média do Vale do Ribieira (SP) para Mineralizações Auríferas, obtida de um Sistema de Informação Geográfica -SIG. Dissertação de Mestrado, Instituto de Geociências, UNICAMP, 110 p.

Paoliello M.B. 2002. Exposição humana ao chumbo em áreas de mineração, Vale do Ribeira, Brasil. Campinas, Tese de doutoramento, Faculdade de Ciências Médicas, UNICAMP, $239 \mathrm{p}$.

Perrotta M. 1996. Potencial aurífero de uma região no Vale do Ribeira, São Paulo, estimado por modelagem de dados geológicos, geoquímicos, geofisicos e de sensores remotos num SIG. Tese de doutoramento, Institudo de Geociências, USP, $150 \mathrm{p}$.

Perrotta M., Campos Neto M.C. 1999. Potencial aurífero do Vale do Ribeira estimado por meio de um Sistema de Informações Geográficas. Rev. Bras. Geociências, 29:639-648.

Selinus O. \& Esbensen K. 1995. Separating anthropogenic to natural anomalies in environmental geochemistry. J. Geoch. Exp., 50:55-66.

Silva A.F., Francisconi O., Godoy A.M., Batolla Jr. F. 1981. Projeto Integração e Detalhe Geológico no Vale do Ribeira, relatório final. São Paulo, CPRM, 5 volumes.

Souza Filho C.R. 2003. O Relevo das Américas Como Nunca Antes Visto. Revista InfoGEO, 30:42-48.

Toujague R.T. de la. 1999. Arsênio e metais associados na região aurifera do Piririca, Vale do Ribeira - SP, Brasil. Dissertação de Mestrado, Instituto de Geociências, UNICAMP, 56 p.

Manuscrito ID 16628

Submetido em 19 de janeiro de 2010 Aceito em 17 de setembro de 2010 